\title{
Margaret McCartney: Referrals for weight management are a mess
}

\author{
Margaret McCartney general practitioner
}

Glasgow

"GP referral to weight loss programmes is effective, acceptable, and takes 30 seconds," said a Lancet press release. ${ }^{1}$

Paul Aveyard, who led the study, said, "Doctors can be concerned about offending their patients by discussing their weight, but evidence from this trial shows that they should be much less worried. Our study found that a brief, 30 second conversation, followed by help booking the first appointment onto a community weight loss programme, leads to weight loss and is welcomed by patients."

The study involved 137 general practices in England. ${ }^{2}$ To assess eligibility, researchers asked to weigh, measure, and estimate body fat in every patient waiting to see the doctor. Doctors did not raise the issue of weight loss in "emotional consultations" or if they judged it inappropriate-for example, if patients had a short life expectancy or an eating disorder.

Patients who agreed were referred to 12 sessions of a commercial weight loss programme and were asked to return four weeks later. In all, researchers screened 8403 patients, but we're not told how many patients declined this first assessment. Of the 2730 potentially eligible people 467 declined to participate, and another 381 were either withdrawn by their doctor or were excluded because they'd previously had weight management intervention.

Eligibility seems predicated on the idea that only the most committed-potentially, the most successful at weight loss-will achieve a referral

We don't know why $17 \%$ of people invited didn't want to participate, and unless we actively look for harms we won't find them. Thirty seconds may be $5 \%$ of a consultation: to fit this in, what else isn't being done? We hear compelling stories of damage done through routinely offering seemingly sensible advice. $^{3}$
And this wasn't a mere " 30 second" intervention: a team of researchers provided the data doctors needed before they saw patients. The patients themselves then had to make long term, ongoing lifestyle changes: those given advice to lose weight lost an average of $1.04 \mathrm{~kg}$, whereas those who had advice plus the referral to the commercial clinic lost an average of $2.43 \mathrm{~kg}$.

In my areas, at least, referrals for weight management in general practice are a mess. The administrative burden on doctors and patients is overwhelming, and people must satisfy eligibility criteria. These seem predicated on the idea that only the most committed—and, therefore, potentially the most successful at weight loss-will achieve a referral.

The researchers of this study should be congratulated for creating a referral system that seems efficient. It's perhaps this that needs to be trialled most of all: an easy to use, welcoming process designed to make it easy for doctors to refer and for people to attend.

\section{Competing interests: See www.bmj.com/about-bmj/freelance- contributors/margaret-mccartney.}

Provenance and peer review: Commissioned; not externally peer reviewed.

1 Lancet, University of Oxford. Press release: GP referral to weight loss programme is effective, welcomed and takes 30 seconds. 25 Oct 2016. www.ox.ac.uk/news/2016-1025-gp-referral-weight-loss-programme-effective-welcomed-and-takes-30-seconds.

2 Aveyard $\mathrm{P}$, Lewis $\mathrm{A}$, Tearne $\mathrm{S}$, et al. Screening and brief intervention for obesity in primary care: a parallel, two-arm, randomised trial. Lancet 2016;356:2492-500. doi:10.1016/S01406736(16)31893-1 pmid:27789061.

3 Lewis E. Why there's no point telling me to lose weight. BMJ 2015;356:g6845. doi:10. 1136/bmj.g6845 pmid:25603805.

Published by the BMJ Publishing Group Limited. For permission to use (where not already granted under a licence) please go to http://group.bmj.com/group/rights-licensing/ permissions 